\title{
A convivência familiar no processo socioeducativo de adolescentes em privação de liberdade
}

\section{The family's living together in the socio-educational process of adolescents in freedom's deprivation}

\section{La convivencia familiar en el proceso socioeducativo de adolescentes en privación de libertad}

\author{
Fernanda Cavalcanti de Medeiros* \\ Centro de Referência em Direitos Humanos - CRDH, Pernambuco, Rio Grande do \\ Norte, Brasil
}

\author{
Ilana Lemos de Paiva** \\ Universidade Federal do Rio Grande do Norte - UFRN, Pernambuco, Rio Grande do \\ Norte, Brasil
}

\begin{abstract}
RESUMO
O objetivo deste artigo é apresentar os resultados de pesquisa realizada acerca da convivência familiar de adolescentes em cumprimento de medidas socioeducativas de privação de liberdade. Foram realizadas rodas de conversa com familiares, bem como levantamento de informações em torno da participação das famílias nas rotinas socioeducativas, a partir da leitura dos Planos Individuais de Atendimento (PIAs) de quinze adolescentes. 0 método utilizado neste estudo foi o da pesquisa-ação. De modo geral, os relatos apontaram para graves violações à convivência familiar, culpabilização da família e insuficiência nos acompanhamentos às famílias. Enfatiza-se no SINASE a necessidade de apoio e trabalho com familiares dos socioeducandos, partindo-se da compreensão que a cidadania do adolescente não pode ser efetivada se não compartilhada com sua família, bem como da necessidade de mudanças nas condições de vida dessas famílias, para que seja possível vislumbrar formas de inserção e acesso aos bens socialmente produzidos, que superem 0 envolvimento com atos infracionais.
\end{abstract}

Palavras-chave: família, sistema socioeducativo, adolescência.

\begin{abstract}
The aim of this paper is to demonstrate the research results concerning the adolescents' family life in the context of enforcement of socio-educational measures of freedom deprivation. Circular conversations with family were performed and information about the family participation in the socioeducational routine was acquired from the reading of the Individual Care Plans (PIAs) of fifteen adolescents. The method used in this study was action research. In general, the reports point to serious violations in relation to family life, blaming family and lack of families care. It's emphasized on SINASE the necessity of support and work with the families of the
\end{abstract}


adolescents, starting from the comprehension that adolescent's citizenship cannot be effective if it is not shared with his/her family, as well as the necessity of changes in living conditions of these families, to make possible to glimpse ways of insertion and access to socially produced goods, that may overcome the involvement with infraction acts.

Keywords: family, socio-educational system, adolescence.

\section{RESUMEN}

El objetivo de este artículo es presentar los resultados de las investigaciones realizadas sobre la convivencia familiar de adolescentes que cumplen medidas socioeducativas de privación de la libertad. Han sido realizadas ruedas de conversación con los familiares así como han sido levantadas informaciones acerca la participación de las familias en el cotidiano socioeducativo desde la lectura de los Planos Individuales de Atendimiento (PIAs) de quince adolescentes. El método utilizado en este estudio fue la investigación-acción. Generalmente, los relatos han reportado graves violaciones a la convivencia familiar, culpabilización de las familias e insuficiencia en su monitoreo. Se enfatiza en el Sistema Nacional de Atendimiento Socioeducativo (SINASE) brasileño la necesidad de apoyo y trabajo con los familiares de los infractores desde la comprensión que la ciudadanía del adolescente no puede ser efectuada si no compartida con su familia, así como la necesidad de cambio en las condiciones de vida de las referidas familias para que se a posible visualizar las formas de inserción y acceso a los bienes socialmente producidos que superen el envolvimiento con infracciones.

Palabras clabe: família, sistema socioeducativo, adolescencia.

\section{Introdução}

As questões que envolvem os adolescentes pobres e suas famílias relacionam-se aos desdobramentos históricos, no que se refere aos processos de exclusão socioeconômica, política e cultural, impostas pelo capitalismo, desde o processo de colonização do Brasil. Rizinni e Rizinni (2004) defendem que a história das políticas públicas brasileiras, voltadas para crianças e adolescentes pobres e seus familiares, remete a uma longa tradição assistencial repressiva, sobretudo com aqueles em cumprimento de medidas socioeducativas, com políticas paternalistas e higienistas que tinham como principal objetivo a contenção social.

Tal processo pode ser percebido a partir da criação e vigência dos códigos de Menores de 1927 e 1979, primeiras legislações brasileiras voltadas para a população infanto-juvenil, em que o Estado colocava na família a total responsabilidade pelo cuidado e sustento dos "menores". Quando a família era considerada incapaz ou fora dos padrões morais e higiênicos, destituía-se o poder familiar e institucionalizavam-se as crianças e adolescentes, que passavam a ser socializadas em instituições como orfanatos e Casas de Misericórdia, ligadas a grupos da Igreja católica. 
A condição de objetos de intervenção das crianças e adolescentes foi superada apenas com o advento do Estatuto da Criança e do Adolescente (ECA), na década de 1990. O ECA (Lei 8.069/90) emergiu, a partir de uma série de lutas e pressões sociais, como o instrumento legal que visava materializar a Doutrina da Proteção Integral na legislação brasileira e direcionar as políticas de atendimento à população infanto-juvenil no Brasil. Junto ao ECA, o artigo 227 da Constituição Federal implicou, pela primeira vez na história do país, o Estado e a sociedade a dividirem com a família a responsabilidade pela garantia dos direitos das crianças e adolescentes.

A partir do reconhecimento da co-responsabilidade pelos direitos de crianças e adolescentes com a família, a instituição familiar passa, conforme aponta Carvalho (2008), "a ocupar o centro das políticas de proteção social, necessitando de apoio para desenvolver seu potencial protetivo, independente das alterações e mudanças nas composições e arranjos familiares com as quais nos deparamos na contemporaneidade". (pp. 269).

Um marco fundamental nas políticas públicas brasileiras voltadas para o público infanto-juvenil foi o Plano Nacional de Promoção, Proteção e Defesa do Direito de Crianças e Adolescentes à Convivência Familiar e Comunitária, o PNCFC (CNAS/CONANDA 2006). Tal Plano tem como objetivo romper com a cultura de institucionalização de crianças e adolescentes fortemente existente no Brasil, a partir do reconhecimento da importância do paradigma da proteção integral, bem como da indissociabilidade do desenvolvimento da criança e adolescente da convivência com sua família e comunidade.

De fato, é inegável que a família nem sempre se configura como lugar de apoio, cuidado e proteção para os filhos. De acordo com Teixeira (2006), "para muitas crianças e adolescentes a família é espaço das primeiras experiências de abandono, vitimização e violência" (p. 440), e a ideia da família como instituição, que tem sempre caráter protetivo, é apontada pela autora como mito. Entretanto, não se deve ignorar as condições concretas de vida e a falta de acesso aos direitos sociais a que estão expostas grande parte das famílias pobres, e que se relacionam aos problemas sociais como alcoolismo, violência doméstica, abusos e maus tratos à população infanto-juvenil, dentre outras problemáticas. Neste sentido, faz-se fundamental o investimento e a articulação de políticas sociais de atendimento e fortalecimento das famílias das classes subalternas.

Assim, o PNCFC defende 0 investimento nas políticas públicas de atenção à família, desde a prevenção do rompimento dos vínculos familiares, passando pela qualificação no atendimento e acompanhamento dos familiares nos serviços de acolhimento 
institucional e no investimento para o retorno ao convívio com a família de origem.

No que tange especificamente à convivência familiar no sistema socioeducativo, objeto de estudo deste artigo, é preciso considerar a indicação de Teixeira (2006), de que o Sistema Socioeducativo é a área do ECA que menos avançou desde a sua promulgação. Nesta mesma direção, Zamora (2004) explicita que "a questão do jovem em conflito com a Lei e do sistema socioeducativo é o coração do conflito entre a doutrina de proteção e os restos da doutrina de situação irregular, vinda dos antigos paradigmas dos códigos de menores" (p.8). Diante de tais constatações, com objetivo de potencializar a lógica da socialização em detrimento da coerção no contexto socioeducativo, e colocar diretrizes e parâmetros concretos para efetivar as conquistas legais do ECA, foi lançado em 2006, após extenso debate e construção conjunta de atores governamentais e da sociedade civil, documento técnico-operativo para guiar a execução das medidas socioeducativas no Brasil. Posteriormente, no ano de 2012, foi promulgada pela Presidenta Dilma Rousseff a lei 12.594/12, que institui o Sistema Nacional de Atendimento Socioeducativo (SINASE).

O SINASE foi construído em consonância com o PNCFC, que segue a tendência nacional de centralização das políticas públicas na atenção à família e enfatiza o papel dos familiares na socioeducação dos adolescentes, bem como a necessidade de garantir aos mesmos, condições necessárias para o cuidado com os seus jovens. Conforme expõe Veronese (2009), o SINASE é um instrumento jurídico e político que complementa o ECA no que se refere ao ato infracional e as medidas socioeducativas. Trata-se de uma legislação que impõe obrigações e a co-responsabilidade da família, da sociedade e do Estado para a efetivação dos direitos fundamentais dos adolescentes que cometeram ato infracional. E ao Estado, principalmente, cabe a função de investir em políticas sociais que facilitem a concretização desse importante instrumento normativo.

No documento técnico-operacional do SINASE, que deve guiar à implementação e funcionamento das rotinas nas unidades socioeducativas, a família aparece como um dos elementos centrais. Recomenda-se, neste documento, que a família, juntamente com a comunidade, participe ativamente da experiência socioeducativa. Parte-se, portanto, do pressuposto de que tudo o que diz respeito ao adolescente e à sua formação, diz respeito também, extensivamente, à sua família, sendo que sua cidadania não pode ser concretizada se distante de sua comunidade e não compartilhada com sua família.

Em relação às famílias de adolescentes autores de atos infracionais, estudos (Branco, Wagner, \& Demarchi, 2008; Dias, Arpini, \& Simon 2011; Brambilla 2012; Yokomiso, 2013), apontam para a importância do suporte familiar para o cumprimento da medida socioeducativa, 
bem como para a necessidade de se trabalhar a família a partir de programas e atividades que garantam a presença dos familiares no cotidiano dos jovens que cumprem tais medidas. Tais pesquisas revelam a centralidade da família enquanto instituição de suporte e apoio para os adolescentes privados de liberdade, entretanto, essas famílias mostraram-se extremamente fragilizadas, vulneráveis e com pouca capacidade de atuação. Compreende-se que, de fato, a maior parte das famílias de adolescentes em cumprimento de medidas socioeducativas vivencia condições concretas de vida que incluem acesso precário aos direitos sociais básicos, e uma série de problemáticas relacionadas a tal precarização. Entretanto, faz-se fundamental no trabalho com as famílias conhecer e apostar em suas potencialidades para o enfrentamento dos problemas e sofrimentos vivenciados.

Diante da constatação da precariedade nas condições de vida e no acesso aos direitos sociais enfrentadas por significativa parte das famílias de adolescentes que vivenciam a experiência da socioeducação, bem como do panorama de centralização da família nas políticas sociais brasileiras, e, sobretudo, da ênfase colocada na família pelo documento técnico-operacional que guia o SINASE, o presente estudo pretende apresentar os resultados de pesquisa realizada acerca da convivência familiar de adolescentes que cumprem medidas socioeducativas de privação de liberdade. A investigação acerca da convivência familiar no sistema socioeducativo, aqui relatada, é parte de um projeto de mestrado que buscou analisar a inserção da família no processo socioeducativo de adolescentes em privação de liberdade, e teve a convivência familiar como um dos principais eixos de análise que emergiram ao longo do processo de pesquisa.

\section{Método}

O presente estudo é uma pesquisa-ação, de natureza qualitativa. Demo (1998), sustenta, em relação à pesquisa qualitativa, que "qualidade é, sobretudo, participação" (p. 93), e enfatiza o caráter dialético e o papel político das pesquisas qualitativas, visto que "todo conhecimento encontra sentido na finalidade a que serve. Conhecimento não vale por si nem em si, mas como meio para realizar os valores sociais, em termos do bem comum. Qualidade política tem a ver principalmente com a ética do conhecimento, da história, das intervenções" (p.99).

\subsection{Procedimentos de coleta de dados}


A coleta de dados foi realizada em duas etapas complementares: rodas de conversa com familiares de adolescentes em privação de liberdade e análise dos Planos Individuais de atendimento (PIAs) de adolescentes que cumpriam medidas de internação em duas unidades masculinas, nos municípios de Caicó e Mossoró, ambas no estado do Rio Grande do Norte. De acordo com Afonso e Abade (2008), rodas de conversa consistem em um método de trabalho que incentiva a participação e reflexão a partir da busca pelo diálogo entre os participantes, através de postura de escuta e circulação da palavra, bem como do uso de técnicas de dinamização de grupo, podendo ser utilizadas em diversos contextos. Participaram das rodas de conversa desta pesquisa predominantemente mães, mas também pais, irmãs, avós, companheiras e tias de adolescentes. Ocorreram seis encontros com periodicidade mensal, e a média de participantes por encontro foi de quatro a cinco familiares. Os participantes foram avisados pela FUNDAC sobre a pesquisa e convidados em reunião a participarem da mesma.

As rodas de conversa, em geral, iniciavam-se com uma rodada de apresentação, inclusive da pesquisa, visto que geralmente chegavam novos participantes, pelo próprio fluxo de entrada e saída dos adolescentes do sistema socioeducativo. Após a apresentação, realizava-se relaxamento ou técnica de acolhimento, e posteriormente, colocava-se elemento disparador de reflexões para o grupo, como perguntas, vídeos, reportagens, organização de eventos, etc. relacionados ao contexto do sistema socioeducativo, juventude e políticas sociais no Brasil. Os conteúdos, além de expressos verbalmente, emergiram também através da confecção de cartazes, colagens, desenhos, entre outros recursos lúdicos utilizados nas atividades em grupo.

Para o registro das observações no grupo com os familiares foram escritos diários de campo, tanto pela pesquisadora quanto por bolsistas da pesquisa, que foram utilizados para a análise das experiências vivenciadas pelos familiares. Decidiu-se pelo não uso de gravadores de imagens ou voz por partir-se do pressuposto que, diante do medo de represálias para com os seus adolescentes, tais recursos poderiam inibir as participações e falas das famílias.

No que diz respeito à caracterização do atendimento à família no sistema socioeducativo, a partir da análise dos Planos de Atendimento Individual (PIA) dos adolescentes que se encontram em privação de liberdade, objetivou-se conhecer a participação da família na construção do mesmo, uma vez que há, nas diretrizes do SINASE, a indicação de que o PIA deve ser construído conjuntamente pela equipe técnica, 0 adolescente e seus familiares. Além disso, pretendeu-se observar as referências dos técnicos em relação às famílias dos adolescentes, isto é, se existem informações sobre a família, encaminhamentos relacionados às mesmas, observações 
sobre as visitas e momentos em que os familiares se fazem presentes na rotina da unidade socioeducativa, entre outras questões. Foram analisados 15 PIAs, de adolescentes cujos familiares participaram das rodas de conversa ocorridas na primeira etapa da pesquisa.

\subsection{Procedimentos de análise de dados}

No que se refere aos procedimentos de análise de dados, após o trabalho de transcrição e compilação dos conteúdos provenientes de todos os diários de campo, bem como dos PIAs dos adolescentes, foi iniciada a primeira fase analítica, ou pré-análise, em que foram realizadas as leituras dos conteúdos coletados com o objetivo de sistematizar algumas ideias iniciais e esboçar esquemas de análise. Posteriormente, a partir da leitura de todo o material compilado, foram identificadas categorias de discussão e o conteúdo da pesquisa foi dividido em eixos analíticos, dentre eles o eixo acerca da convivência familiar e comunitária, que será apresentado a seguir.

\subsection{Procedimentos éticos}

O acesso aos PIAs foi autorizado pela Fundação Estadual da Criança e do Adolescente (FUNDAC), autarquia responsável pela execução das medidas socioeducativas de restrição e privação de liberdade no Rio Grande do Norte, para fins de pesquisa, a partir do compromisso da pesquisadora com o cuidado em relação à preservação das identidades dos participantes. Nesse sentido, só participaram da pesquisa as famílias que compreenderam a proposta da mesma e expressaram voluntariamente o desejo de participar do estudo. Os participantes demonstraram consentimento no uso de suas informações na pesquisa através de Termo de Consentimento Livre e Esclarecido (TCLE). O trabalho foi submetido ao Comitê de Ética em Pesquisa da UFRN e aprovado através do parecer consubstanciado $n^{\circ}$ 752.346.

Os dados foram compilados e analisados à luz da teoria marxista, que embasa este estudo, partindo da compreensão dos fatores que permeiam o sistema socioeducativo enquanto desdobramentos e expressões da "questão social" ${ }^{1}$. A partir deste referencial teórico é possível problematizar os processos de criminalização e extermínio da juventude pobre, bem como a fragilidade das políticas públicas, que no contexto socioeducativo se expressa tanto na execução das próprias medidas como na articulação da rede de serviços para a proteção do adolescente e o fortalecimento de sua família.

\section{Resultados e discussão}


Durante os encontros com familiares de adolescentes em cumprimento de medidas socioeducativas de privação de liberdade, emergiram uma série de angustias, dúvidas e inquietações acerca das condições vivenciadas pelos seus adolescentes no cumprimento das medidas. De forma geral, a maior parte dos conteúdos discutidos nesses encontros girou em torno das violações à convivência familiar e suas consequências. Por ser tratar de uma pesquisa-ação, foram realizadas atividades e dinâmicas de sensibilização com esses familiares, para que compartilhassem suas dores e pudessem trocar experiências e estratégias de enfrentamento. Além disso, a partir de solicitações dos participantes, foram realizadas oficinas temáticas, com uso de recursos visuais e realização de dinâmicas e discussões acerca do ECA, SINASE e Sistema de Garantia de Direitos.

A ênfase colocada pelos participantes, ao longo dos encontros, na violação à convivência familiar, pode ser compreendida a partir da própria configuração do sistema socioeducativo no $R N$, que é composto por oito unidades, sendo quatro na capital do estado (Natal), e três no interior, entre internação masculina, feminina e semiliberdade. Todas as instituições se encontram com interdição parcial ou total pela justiça. Entre as unidades totalmente interditadas encontra-se o Centro Educacional (CEDUC) Pitimbu, unidade de internação masculina que atende adolescentes da capital e toda a região metropolitana, interditado desde o ano de 2012, por problemas na estrutura física, hidráulica e elétrica, conforme divulgado pelo Tribunal de Justiça (TJ) do Rio Grande do Norte. ${ }^{2}$

Diante da impossibilidade de internação de adolescentes na capital, e da pressão midiática e social para que os adolescentes autores de atos infracionais não ficassem às soltas pela cidade, foi feito um acordo entre Fundac e poder judiciário, em que os adolescentes da capital e região metropolitana - que fossem sentenciados ao cumprimento de medidas de privação de liberdade - seriam encaminhados para as unidades de internação do interior. Tal situação e suas implicações foram divulgadas em diversas reportagens de jornais tanto do RN quanto de circulação nacional. ${ }^{3}$ Esta transferência dos adolescentes da capital para as unidades do interior do estado causou sérios transtornos, os quais foram aqui abordados brevemente.

No instrumento técnico-operacional que guia a organização do sistema de atendimento socioeducativo, é colocada a necessidade de que os familiares participem ativamente de todo o processo socioeducativo dos adolescentes, e, para isso, direcionam-se à realização de atividades e ações que, considerando a realidade e as condições de vida das famílias, possibilitem o fortalecimento dos vínculos familiares. Com a distância geográfica dos adolescentes e familiares já era possível inferir que a convivência familiar, no sistema socioeducativo do Rio Grande do Norte estaria 
comprometida. As falas de familiares não apenas confirmaram tal afirmação, mas deram a dimensão das violações.

Nas rodas de conversa com os familiares foram relatadas uma série de situações violadoras, que geravam na família a sensação de impotência e desamparo, como a irregularidade e precariedade das visitas. A FUNDAC disponibilizava periodicamente ônibus para levar as famílias de adolescentes de Natal e região metropolitana para as unidades de internação de Mossoró e Caicó para as visitas familiares. Houve vários episódios de quebra dos ônibus, que demoravam longos períodos para serem consertados, fazendo com que os familiares passassem semanas ou meses sem ver os seus filhos. Além disso, a periodicidade das visitas oscilava entre quinzenais e mensais, o que gerou grande revolta entre os familiares, como pode ser percebido nos seguintes depoimentos: "Não sou bola de sinuca para estar toda hora de lá para cá, sem saber nem o que está acontecendo". (Mãe, 33 anos). "Porque o certo era o Ceduc daqui abrir. Todo dia eu peço a Deus por isso". (Mãe, 39 anos).

A segunda fala dimensiona o desespero materno, ao ponto de "pedir a Deus" a reabertura de um serviço precário e que, na prática, funcionava apenas enquanto espaço de encarceramento de seu filho, mas que diante da situação posta na atualidade, aparece como uma alternativa menos nociva do que a vivida, em que não é possível acompanhar e garantir com periodicidade nem mesmo a visita ao adolescente. Diante de tal quadro, deparamo-nos com o sofrimento ético-político, que segundo Sawaia (1999) relaciona-se com a dor originada da situação social de ser tratado como inferior, subalterno e incapaz. Qualquer separação de um adolescente da sua família, por diferentes motivos, gera impactos no desenvolvimento do mesmo e nas relações e vivências da família. Entretanto, a separação vivenciada nesse contexto do sistema socioeducativo, além de causar o sofrimento existencial pela separação em si, é negativamente alimentada pela perversidade da separação, dos medos, angústias, revoltas e humilhações vivenciadas ao longo de tal processo por adolescentes e suas famílias.

Além do motorista, técnicos e educadores da FUNDAC acompanhavam as famílias nas viagens para as visitas nas unidades de privação de liberdade do interior do estado. Os familiares compartilharam, ao longo dos encontros, as condições precárias e violadoras que marcavam a viagem. Segundo os familiares, tais condições incluíam humilhações por parte dos funcionários, falta de informações e desconsideração das necessidades dos familiares, conforme pode ser percebido no depoimento de um participante do grupo: "O que acontece dentro do carro é crítico, o povo vai apertado, vomitando. Da última vez teve uma mãe que defecou dentro do ônibus por medo e vergonha de pedir ao motorista para parar". (Pai, 43 anos). 
Para a ocorrência de situações tão extremas quanto à narrada pelo participante, é possível inferir o tipo de relação estabelecida entre os familiares e os profissionais que compõe o sistema socioeducativo no Rio Grande do Norte. Relação esta que, a partir das observações e diálogos com os familiares, não parece se amparar no respeito à dignidade humana. Tais experiências e vivências negativas emergiram como mais um fator de afastamento dos familiares da rotina dos seus adolescentes privados de liberdade.

As visitas quinzenais, geralmente, ocorriam em dias de sexta-feira, iniciando-se por volta das $10 \mathrm{~h}$ da manhã, podendo permanecer até as $16 \mathrm{~h}$, sendo que, na maioria das vezes, não duravam até o limite do horário, não por escolha dos familiares, mas pela necessidade da viagem de retorno a capital, com duração de cerca de quatro horas. $\mathrm{Na}$ chegada à unidade, os familiares passavam pelos procedimentos de revista e guarda de pertences, para, posteriormente, encontrarem-se com os filhos. Durante as visitas, as famílias utilizam todo o tempo disponível para conversar e ficar próximos aos adolescentes, não havendo maiores contatos com as equipes técnicas da unidade. Por outro lado, devido à distância entre a unidade e os municípios de origem dos adolescentes, os profissionais, em geral, não conseguem realizar visitas ou acompanhamentos junto aos familiares.

Ainda no tocante às visitas, outra temática que emergiu no grupo de famílias foi a questão da visita íntima, sendo reivindicação de alguns familiares, como o senhor A., 43 anos, que compartilhou com o grupo que seu filho sempre solicita visita de sua a namorada, e que "como todos os jovens, eles precisam de sexo". O Rio Grande do Norte foi um dos primeiros estados brasileiros a ter espaços físicos reservados para as visitas íntimas, entretanto, à época da coleta de dados desta pesquisa, estas estavam suspensas e sem previsão de retorno. Tal situação aponta, novamente, para o descumprimento das diretrizes apontadas pelo documento técnico-operativo do SINASE para execução das medidas socioeducativas de privação de liberdade, visto que, neste documento, ressalta-se a importância de se considerar a sexualidade no desenvolvimento do adolescente. Além disso, é importante observar a importância das visitas íntimas na manutenção dos vínculos familiares, já que muitos adolescentes já constituíram seu próprio núcleo familiar, devendo suas companheiras ser consideradas enquanto familiares, já que o conceito de família é mais amplo do que laços consanguíneos, e diz respeito, sobretudo, às relações de pertencimento e afeto entre os seus membros. Os familiares apontaram, em suas falas, um maior reconhecimento da realidade de seus adolescentes, que de fato iniciam suas vivências sexuais e reprodutivas precocemente, assim como o fazem com a entrada no mercado de trabalho e na assunção de responsabilidades 
do "mundo adulto", que os filhos da classe média e alta só o farão, em geral, com idade bem mais avançada.

Ao longo dos encontros com os familiares, tornou-se evidente o quão remotas e insipientes são as ações voltadas para o fortalecimento familiar. O único encaminhamento referido pelas famílias foi o de irmãs e irmãos dos adolescentes privados de liberdade para cursos do Programa Nacional de Acesso ao Ensino Técnico e Emprego (PRONATEC). A carência de práticas e encaminhamentos voltados para o fortalecimento da família e dos vínculos familiares dos adolescentes em cumprimento de medidas socioeducativas também foi evidenciada, a partir da caracterização dos PIAS dos adolescentes. Em geral, nestes documentos, estavam descritas as condições materiais das famílias, mas havia pouca referência a ações da equipe voltadas para o atendimento aos familiares.

Foi possível observar que, mesmo quando existem ações e encaminhamentos voltados à família, eles nem sempre são propostos e realizados a partir da observação das necessidades da própria família, mas parecem buscar muito mais um sentido de proteção da sociedade aos riscos que o adolescente representa. Além disso, quando questionados acerca dos PIAS, os familiares demonstraram total desconhecimento do que se tratava.

As informações contidas nos PIAs acessados nesta pesquisa corroboraram com as falas dos familiares acerca da violação à convivência familiar. Em um dos documentos analisados havia o seguinte registro: "Os contatos da família do educando tem sido por telefone, haja vista residirem em Natal, e o genitor (avô) se encontra desempregado sem a condição necessária para viajar." (PIA 06). Esta é uma informação que precisa ser analisada, visto que ela se encerra na falta de condições financeiras do familiar, naturalizando, de certa forma, a situação de violação. Além disso, de modo geral, é possível perceber que os encaminhamentos à família são pensados apenas em relação aos programas de transferência de renda, a partir da avaliação se a família possui ou não perfil para ser beneficiária de programas como o Programa Bolsa Família (PBF). Encaminhamentos para tais programas são relevantes no contexto de pobreza e extrema pobreza, entretanto, faz-se fundamental realizar também encaminhamentos para serviços de saúde, programas de educação, trabalho e habitação, dentre outras possibilidades.

Outro aspecto preocupante observado nos PIAs é o uso de termos genéricos e repetidos acerca das relações e participação da família na vivência socioeducativa do adolescente, que apontam para a dificuldade de um real acompanhamento familiar por parte das equipes técnicas que compõem as unidades. Percebeu-se também o uso de expressões e observações repetidas nos documentos de diferentes adolescentes e a falta de compreensão acerca de questões relativas a gênero e relações familiares, por exemplo. 
Uma grave prática observada nos documentos consultados é a culpabilização da família, que aparece explicitamente em termos amplamente utilizados como "famílias desestruturadas" e, de forma indireta, em expressões como "mãe muito permissiva", que supostamente explicariam 0 envolvimento do adolescente no contexto dos atos infracionais. Tal concepção de profissionais acerca das famílias gera uma série de tensionamentos com os familiares, e conforme estes explicitaram nas rodas de conversa, são eles que acabam tendo que ceder e se submeter a "lei do silêncio", visto que questionamentos e denúncias ao Ministério Público, órgãos de Direitos Humanos e de controle das políticas públicas, tem como contrapartida mais castigos e punições nos corpos e mentes dos seus adolescentes.

Nesse sentido, Mioto (2010) atenta que, apesar dos avanços proporcionados pelo ECA, como a diretriz de implementação de programas de orientação e apoio sociofamiliar, que objetivam garantir o direito à convivência familiar e comunitária, muitas vezes tais programas trazem embutidos princípios assistencialistas e normatizadores da vida familiar que imaginávamos ultrapassados. A autora aborda a complexidade da relação família-Estado, pelo viés controlador do Estado sob o comportamento dos indivíduos e famílias, visto que "o surgimento do Estado, contemporâneo ao nascimento da família moderna como espaço privado e lugar dos afetos, não significou apenas uma separação de esferas. Significou também o estabelecimento de uma relação entre eles, até hoje conflituosa e contraditória". (p.45).

Mioto (2010) preocupa-se, ainda, com a disseminação do termo "famílias desestruturadas", que passou a ser intensamente utilizado no senso comum, pela mídia e por técnicos que atuam junto às famílias na execução das políticas sociais. A implicação do uso de tal termo é a difusão da ideia de que as famílias que precisam da "ajuda" pública são aquelas que falharam, fracassaram no cuidado com os seus filhos, atestando uma suposta falência e incapacidade das famílias pobres, culpabilizando-as, e ignorando ou ocultando a base material das precárias condições de vida de grande parte destas famílias brasileiras:

Diante disso, pode-se afirmar que não é apenas por uma questão semântica que o termo "famílias desestruturadas" continua sendo de uso corrente. Cada vez mais ele é utilizado para nomear as famílias que falharam no desempenho das funções de cuidado e proteção dos seus membros e trazem dentro de si as expressões de seus fracassos, como alcoolismo, violências e abandonos. Assim, se ratifica a tendência de soluções residuais aos problemas familiares. (p. 54). 
Apesar da culpabilização atribuída aos familiares pelas vivências e envolvimentos dos adolescentes com atividades ilícitas, foi possível perceber, no campo final dos PIAs, que contém o parecer técnico acerca da progressão da medida, a consideração das relações e do apoio familiar como elemento central para subsidiar as decisões relativas à progressão das medidas. Importante ressaltar que a culpabilização das famílias pelos profissionais é um processo que envolve assimilação de discurso midiático de criminalização da pobreza e apelo à punição, e que a falta de compreensão e de encaminhamentos mais efetivos junto aos familiares relaciona-se não exclusivamente à falta de vontade individual dos profissionais, mas às condições precárias para a realização das atividades e ao sucateamento de um sistema socioeducativo que, apesar dos avanços legais conquistados com o SINASE, continua funcionando de forma precária, partindo da lógica do encarceramento da juventude pobre.

As consequências da violação à convivência familiar, bem como da violência institucional no sistema socioeducativo, expressa, por exemplo, por práticas de violência física e torturas cometidas por educadores e policiais nas unidades, além de total descaso no acesso dos adolescentes a serviços de saúde e educação, e do próprio envolvimento dos adolescentes com atos infracionais, também estão registradas nos Planos Individuais de Atendimento dos Adolescentes. Foram observados registros nos PIAs e depoimentos nas rodas de conversa relatos de situações de mães e pais hospitalizados devido ao sofrimento das situações vivenciadas pelos seus filhos ao longo de todo o processo de envolvimento do adolescentes com atividade ilícitas, cometimento do ato infracional e cumprimento da medida socioeducativa de privação de liberdade. Outra informação relevante é que parte dos adolescentes que cumprem medidas de internação contribuía significativamente com a renda familiar, a partir de "bicos" e empregos informais, inclusive junto com a família em pequenos negócios, como vendas de produtos em feiras, de lanches e bebidas.

Predominantemente, as mães eram as responsáveis pelos adolescentes nas unidades de internação, e, de modo geral, as responsáveis financeiras pelas suas famílias. Destacaram-se, em nossa análise, a presença de avós e de namoradas, esposas e companheiras dos núcleos familiares já constituídos pelos adolescentes. Alguns adolescentes não possuíam vínculos familiares, tendo crescido em situação de rua ou perpassando unidades de acolhimento institucional, em um ciclo de institucionalização complexo e perverso.

Por fim, um tema apontado, tanto nos diálogos com familiares, quanto nos PIAs, foi a questão das fugas e evasões, que notoriamente aumentaram após o envio de adolescentes da capital para o cumprimento das medidas no interior, longe de suas famílias e comunidades. Um dos maiores dilemas compartilhados pelos 
familiares foi a situação de ter os filhos evadidos, em casa, como pode ser observado na fala da participante S.: "O meu (filho) fugiu e infelizmente está em casa, mas eu não aceito, quero que ele procure uma unidade pra pagar pelo que ele fez.". (Mãe, 41 anos).

As mães e pais, em sua maioria, colocavam o desejo de que 0 adolescente "pagasse sua dívida com a justiça", entretanto, temiam, por outro lado, a permanência dos jovens nas unidades, visto o cotidiano de torturas e os casos de morte de adolescentes ocorridos nestes ambientes, que como expomos anteriormente, levaram a justiça a interditar totalmente ou parcialmente todas as unidades de privação/restrição de liberdade no estado do Rio Grande do Norte.

Além disso, foram identificadas práticas institucionais violadoras, como a revista íntima vexatória, em que os familiares são revistados por agentes policiais ou educadores, sendo obrigados a se despir e realizar agachamentos com espelhos abaixo de suas genitálias, para busca de drogas, celulares e objetos que tem a entrada proibida nas unidades. As famílias relataram situações constrangedoras como procedimentos realizados sem luvas pelas agentes, revistas íntimas em idosas, bebês e crianças, dentre outras situações que, além de violar gravemente a dignidade humana, afastam ainda mais as famílias dos adolescentes que cumprem as medidas de privação de liberdade. Segundo relato dos familiares nas rodas de conversa, muitas vezes, os próprios adolescentes pedem as suas mães, avós e companheiras para não os visitarem temendo o constrangimento e sofrimento ocasionado pela revista íntima.

\section{Considerações finais}

Este artigo teve como objetivo apresentar os resultados de pesquisa realizada acerca da convivência familiar no contexto do sistema socioeducativo. Para tal, aproximamo-nos dos familiares dos adolescentes que cumpriam medidas de internação nas unidades de Mossoró e Caicó, ouvindo, testemunhando e compartilhando as suas dúvidas, angústias, medos, revoltas e também a sua força e a luta pela vida dos seus adolescentes.

Os resultados desta pesquisa, expostos na sessão anterior, corroboram com estudos que apontaram a importância da família no cumprimento das medidas socioeducativas pelos adolescentes (Branco, Wagner, \& Demarchi, 2008; Dias, Arpini, \& Simon 2011; Brambilla 2012; Yokomiso, 2013). Observamos durante a realização desta pesquisa, um sistema socioeducativo que tem violações em suas bases e pune indivíduos de classe social bem definida: adolescentes provenientes de famílias que vivem em situação de pobreza e extrema pobreza. Tal sistema, pelas limitações de recursos humanos (número de profissionais e qualificação dos profissionais) e 
estruturais (internet, carros para visitas, estrutura das unidades, etc.) não consegue atender de forma adequada, com acompanhamentos e encaminhamentos relevantes, nem os adolescentes e nem as suas famílias, violando inclusive a convivência familiar, direito basilar para todos os seres humanos, especialmente para aqueles que se encontram em situação peculiar de desenvolvimento, como os adolescentes.

Durante todas as etapas desta pesquisa, desde a coleta até análise dos dados, encontramos contradições entre os avanços legais promovidos pelo ECA, SINASE e PNCFC, e a realização dos serviços de forma sucateada, desqualificada, desconectada e violadora dos direitos de adolescentes e familiares, o que ocorre não apenas no âmbito do sistema socioeducativo, mas marca a execução das políticas públicas e sociais no capitalismo periférico. É importante considerar que o SINASE é uma legislação nova, com pouco mais de dois anos, e que seguirá um longo processo na busca de sua efetivação. Entretanto, a partir dos relatos das famílias, é possível perceber a continuidade de ações e lógicas anteriores ao ECA, que remontam aos Códigos de Menores, ou violações tão intensas, que mesmos nestes já seriam consideradas graves. Segue-se, na prática, partindo-se da lógica de serviços pobres e precários, para a população pobre.

Tratando-se de adolescentes pobres que se envolvem em práticas ilícitas e chegam ao sistema socioeducativo, então, o Estado encontra apoio da mídia e sociedade para a realização de serviços precários, que tem a punição como elemento-chave em todos os seus eixos (estrutura física, alimentação, tratamento aos familiares, etc.), pois, como defende Wacquant $(2003 ;$ 2008) o Estado Penal, que se coloca enquanto autoridade no campo penal para compensar sua ausência de poder no campo social e econômico, tem como um de seus principais pilares o discurso da meritocracia, em que o indivíduo é o único responsável por seu sucesso ou fracasso, tendo tal responsabilidade individual como contrapartida a irresponsabilidade coletiva. Tal lógica gera a culpabilização e demonização de "classes perigosas", dentre elas a dos adolescentes residentes em periferias e que perpassam pela socioeducação.

Temos, na prática, um sistema socioeducativo punitivo e em que a educação ainda se faz bastante distante. Nesse sentido, corroboramos com Teixeira (2006), quando a autora alerta que, nas condições atuais da socioeducação brasileira, sobretudo nas unidades de privação de liberdade, não é possível se pensar em educação, pois "qual é a educação possível em condições nas quais não existe 0 valor da dignidade?" (p.442)

Por se tratar de uma pesquisa-ação, além da coleta, análise e publicização dos resultados, foram realizadas uma série de atividades e eventos junto às famílias, como mesas redondas com atores que 
compõe o sistema socioeducativo, manifestações e entrega de carta com reivindicações de superação das violações que acometem familiares e adolescentes que vivenciam a realidade do sistema socioeducativo, além da realização de oficinas sobre direitos para as famílias, solicitadas pelos próprios familiares, após as primeiras rodas de conversa. Consideramos que tais ações foram relevantes pela possibilidade de coletivização das problemáticas vividas, e busca conjunta pela superação das mesmas, entretanto, sem perder de vista questões macroestruturais, como a criminalização e extermínio da juventude pobre e o sucateamento das políticas públicas, fenômenos que são naturalizados na sociedade capitalista, mas que precisam ser questionados e ter seus determinantes desvelados, no processo de busca pela superação dos mesmos.

O estudo teve entre suas principais limitações o recorte geográfico, uma vez que a presente pesquisa foi realizada apenas no estado do Rio Grande do Norte, bem como limitações relacionadas ao tempo de observação, período em que a unidade de privação de liberdade da capital encontrou-se interditada. Apesar de tais especificidades, acreditamos, a partir da observação de relatórios de órgãos de controle (CNJ 2010; CNMP 2013), e de estudos de autores que se debruçam acerca da realidade do sistema socioeducativo no Brasil como Volpi (2008) quando afirma que "Não é possível dizer que as autoridades não saibam o que está acontecendo, porque este país tem pesquisadores, tem estudiosos em todas as áreas. Todos já sabem, há muito tempo, que o sistema é um equívoco para os adolescentes", que de forma geral, as violações aos adolescentes e famílias apresentadas nesta pesquisa representam algumas das principais problemáticas que perpassam a realidade socioeducativa brasileira.

Reafirmamos, portanto, nossa compreensão dos problemas e violações que compõe o sistema socioeducativo enquanto uma grave e perversa expressão da "questão social". Assim, sua superação não ocorrerá de forma pontual, com proposições simplistas como a redução da idade penal ou investimento na construção de mais unidades e ampliação do tempo de internação, mas a partir de mudanças concretas nas condições de vida dos jovens pobres e suas famílias, para que seja possível vislumbrar formas de inserção e acesso aos bens socialmente produzidos, que vão além do envolvimento com atos infracionais.

\section{Referências}

Adolescentes perigosos estão na rua por falta de vagas (2014, 10 de janeiro). G1 Rio Grande do Norte. Recuperado de http://g1.globo.com/rn/rio-grande-do-norte/noticia/2014/01/ 
Afonso, M. L. M., \& Abade, F. (2008). Para reinventar as Rodas. Belo Horizonte: Rede de cidadania Mateus Afonso de Medeiros (RECIMAM). Publicação eletrônica. Recuperado em 15 de dezembro, 2014, de: http://www.ufsj.edu.br/portalrepositorio/File/lapip/PARA_REINVENTAR_AS_RODAS.pdf

Branco, B. M., Wagner, A., \& Demarchi, K. A. (2008). Adolescentes infratores: Rede Social e Funcionamento familiar. Psicologia: Reflexão e Crítica, 21(1), 125-132.

Brambilla, B. B. (2012). Percepção de Suporte Familiar de Adolescentes em Conflito com a Lei. Dissertação de mestrado, Universidade Metodista de São Paulo, São Bernardo do Campo, SP, Brasil.

Carvalho, M. C. B. (2008). Famílias e políticas públicas. In A. N. Acosta, \& M. A. F. Vitale (Orgs.). Família: redes, laços e políticas públicas ( $5^{\circ}$ ed.). São Paulo: Cortez.

Conselho Nacional de Justiça (2010). Projeto Justiça ao Jovem (relatório acerca das unidades de privação de liberdade do sistema socioeducativo brasileiro/2010). Brasília: CNJ.

Conselho Nacional do Ministério Público. (2013). Relatório da infância e juventude - Resolução n 67/2011: Um olhar mais atento às unidades de internação e semiliberdade para adolescentes. Brasília, CNMP.

Demo, P. (1998). Pesquisa Qualitativa: busca de equilíbrio entre forma e conteúdo. Revista Latino-americana de Enfermagem, 6(2) 89-104.

Dias, A. C. G., Arpini, D. M., \& Simon, B. R. (2011). Um olhar sobre a família de jovens que cumprem medidas socioeducativas. Psicologia \& Sociedade, 23(3), 526-535.

Em 10 anos, morte de jovens aumenta 1000\% em Natal. (2013, 24 de março). Folha de São Paulo. São Paulo. Recuperado de http://www1.folha.uol.com.br/fsp/cotidiano/100245-em-10anos-morte-de-jovens-aumenta-1000-em-natal.shtml

Juiza mantém interdição do Ceduc Pitimbu (2012, 29 de agosto). Tribunal de Justiça do estado do Rio Grande do Norte. Recuperado de http://www.tjrn.jus.br/index.php/comunicacao/noticias/1125juiza-mantem-interdicao-do-ceduc-pitimbu

Lei 8.069 (1990, 13 de julho). Institui o Estatuto da Criança e do Adolescente. Brasília-DF: Presidência da República. Recuperado de http://www.planalto.gov.br/ccivil_03/leis/l8069.htm

Lei 12.594 (2012, 18 de abril). Institui o Sistema Nacional de Atendimento Socioeducativo. Brasília-DF: Secretaria Nacional de Direitos Humanos da Presidência da República. Recuperado de http://www.planalto.gov.br/ccivil_03/_ato20112014/2012/lei/l12594.htm 
Mioto, R. C. T. (2010). Novas propostas e velhos princípios: a assistência às famílias no contexto de programas de orientação e apoio sociofamiliar. In Sales, M. A., Matos, M. C. \& Leal, M. C. (Org.). Política social, família e juventude: uma questão de direitos. (pp. 26-43) (60 ed). São Paulo: Cortez.

Netto, J. P. \& Braz, M. (2006). Economia Política: uma introdução crítica. São Paulo: Cortez.

Plano Nacional de Promoção, Proteção e Defesa do Direito de Crianças e Adolescentes à Convivência Familiar e Comunitária. (2006, 13 de dezembro). Recuperado de http://www.dhnet.org.br/dados/pp/a_pdfdht/plano_nacional_co nvivencia_familiar_comunitaria.pdf

Rizzini, I., \& Rizzini, I. (2004). A institucionalização de crianças no Brasil: percurso histórico e desafios do presente. Rio de Janeiro: Ed. PUC-Rio.

Sawaia, B. B. (1999). Artimanhas da Exclusão. Petrópolis: Editora Vozes.

Teixeira, M. L. T. (2006). Evitar o desperdício de vidas. In ILANUD, ABMO, SEDH, UNFPA (Org.). Justiça Adolescente $e$ ato infracional: socioeducação e responsabilização. (pp. 427-448). São Paulo: ILANUD.

Veronese, J. R., \& Lima, F. S. (2009). O Sistema Nacional de Atendimento Socioeducativo (SINASE): Breves considerações. Revista Brasileira Adolescência e Conflitualidade, 1(1) 29-46.

Wacquant, L. (2003). Punir os Pobres: a nova gestão da miséria nos Estados Unidos. Rio de Janeiro: Revan.

Wacquant, L. (2008). As duas faces do gueto. São Paulo: Boitempo.

Yokomiso, C. T. (2013). Família, Comunidade e Medidas Socioeducativas: os espaços psíquicos compartilhados e a transformação da violência. Tese de doutorado, Universidade de São Paulo, São Paulo, SP, Brasil.

Zamora, M. H. (2004). Otra América Latina para los niños y adolescentes. In: I. Rizzini, M. H. Zamora, \& R. Fletes (Orgs.). Niños y adolecentes creciendo en contextos de pobreza, marginalidad y violencia en América Latina. (pp. 14-27). Rio de Janeiro: Editora PUC-Rio, CIESPI, Childwatch Internacional.

\section{Endereço para correspondência}

\section{Fernanda Cavalcanti de Medeiros}

Centro de Referência em Direitos Humanos

Av. Gustavo Guedes, 1880, Cidade Jardim, CEP 59078-380, Natal - RN, Brasil

Endereço eletrônico: fernandacmedeiros@gmail.com

\section{Ilana Lemos de Paiva}

Universidade Federal do Rio Grande do Norte

Pós-Graduação em Psicologia - CCHLA

Campus Universitário, Lagoa Nova, CEP 59078-970, Natal - RN, Brasil

Endereço eletrônico: ilanapaiva@hotmail.com 
Recebido em: 18/01/2015

Reformulado em: 22/04/2015

Aceito para publicação em: 27/04/2015

\section{Notas}

* Psicóloga do Centro de Referência em Direitos Humanos (CRDH). Mestranda do Programa de Pós-Graduação em Psicologia da Universidade Federal do Rio Grande do Norte (UFRN), Natal, Brasil.

** Psicóloga. Doutora em Psicologia pela Universidade Federal do Rio Grande do Norte. Docente pesquisadora do Programa de Pós-Graduação em Psicologia da UFRN, Natal, Brasil. Coordenadora do Observatório da População Infanto-juvenil em Contextos de Violência (OBIJUV).

${ }^{1}$ Quando nos referimos à "Questão Social", compreendemos que, como apontam Netto e Braz (2006), trata-se de questão oriunda do processo de desigualdade aqui entendida como distribuição diferenciada dos bens socialmente produzidos intensificado no modo de produção capitalista, que produz uma generalização exacerbada da pobreza, ao mesmo tempo em que se aumenta consideravelmente a capacidade de se produzir riquezas.

2 http://www.tjrn.jus.br/index.php/comunicacao/noticias/1125-juiza-manteminterdicao-do-ceduc-pitimbu

${ }^{3}$ Reportagem publicada no jornal Folha de S. Paulo no dia 24/03/2013. Disponível em http://www1.folha.uol.com.br/cotidiano/2013/03/1251563-em-10-anos-mortede-jovens-aumenta-1000-em-natal-rn.shtml 